\title{
Contribuição à taxonomia de três tribos de Lamiinae (Coleoptera, Cerambycidae)
}

\author{
Maria Helena M. Galileo ${ }^{1,3}$ \& Ubirajara R. Martins ${ }^{2,3}$
}

1. Museu de Ciências Naturais, Fundação Zoobotânica do Rio Grande do Sul, Caixa Postal 1188, 90001-970 Porto Alegre, RS, Brasil.
2. Museu de Zoologia, Universidade de São Paulo, Caixa Postal 42494, 04218-970 São Paulo, SP, Brasil.
3. Pesquisador do CNPq.

\begin{abstract}
Contribution to the taxonomy of three tribes of Lamiinae (Coleoptera, Cerambycidae). New species described - Onciderini: Hypsioma solangeae sp. nov. from Brazil (Mato Grosso?) and Hypsioma cariua sp. nov. from Bolivia (Santa Cruz); Hemilophini: Piratininga mocoia sp. nov. and Eranina piterpe sp. nov. both from Bolivia (Santa Cruz); Aerenicini: Phaula atyroa sp. nov. from Brazil (Mato Grosso do Sul) and Aerenicopsis rejaneae sp. nov. from Brazil (Tocantins). A colored figure of Oncideres fulvoguttata Dillon \& Dillon, 1946 is provided. Illustrations of two species of Phaula, P. lichenigera (Perty, 1832) and P. splendida (Galileo \& Martins, 1987) are given for comparisons with P. atyroa sp. nov.
\end{abstract}

KEYWORDS. Aerenicini, Hemilophini, Onciderini, new species, taxonomy.

RESUMO. Novas espécies são descritas em Onciderini: Hypsioma solangeae sp. nov., do Brasil (Mato Grosso ?) e Hypsioma cariua sp. nov., da Bolívia (Santa Cruz); Hemilophini: Piratininga mocoia sp. nov. e Eranina piterpe, sp. nov., ambas da Bolívia (Santa Cruz); Aerenicini: Phaula atyroa sp. nov., do Brasil (Mato Grosso do Sul) e Aerenicopisis rejaneae sp. nov., do Brasil (Tocantins). Figuramos a cores Oncideres fulvoguttata Dillon \& Dillon, 1946. Duas espécies de Phaula, P. lichenigera (Perty, 1832) e P. splendida (Galileo \& Martins, 1987) são figuradas para comparação com Phaula atyroa sp. nov.

PALAVRAS-CHAVE. Aerenicini, Hemilophini, Onciderini, espécies novas, taxonomia.

Baseados em material do Museu de Zoologia da Universidade de São Paulo, São Paulo (MZSP) e do American Coleoptera Museum, San Antonio (ACMB), descrevemos e ilustramos espécies novas e já descritas. Por determinação de James E. Wappes (ACMB), holótipos das espécies bolivianas pertencentes à sua coleção devem ser depositados no Museo Noel Kempff Mercado, Santa Cruz (MNKM).

Na tribo Onciderini descrevemos duas espécies no gênero Hypsioma Audinet-Serville, 1835, gênero que atualmente envolve 26 espécies. Foi publicada uma chave para identificação das espécies por Dillon \& DilloN (1945) quando o gênero continha 21 espécies. Nesta contribuição descrevemos mais duas, $H$. cariua sp. nov. da Bolívia e H. solangeae sp. nov. de "Mato Grosso", Brasil, provavelmente coletado antes da divisão do Estado de Mato Grosso (etiqueta antiga). Também ilustramos a cores Oncideres fulvoguttata Dillon \& Dillon, 1946 da qual se conhece apenas o esquema do padrão do pronoto e dos élitros.

Na tribo Hemilophini, grupo numeroso, com 112 gêneros (Monné, 2005), descrevemos duas novas espécies também da Bolívia: Piratininga mocoia sp. nov. e Eranina piterpe sp. nov., ambas da Bolívia.

Aerenicini foi motivo de revisão por MARTINS \& GALILEO (1998), quando foram considerados 26 gêneros. Uma espécie nova de Phaula Thomson, 1857, P. atyroa sp. nov., é comparada com P. lichenigera (Perty, 1832) e P. splendida Galileo \& Martins, 1987; as três espécies são ilustradas. No gênero Aerenicopsis Bates, 1885, acrescentamos uma espécie procedente do Tocantins (Brasil).

\section{ONCIDERINI \\ Hypsioma solangeae sp. nov. (Fig. 1)}

Etimologia. O epíteto é uma homenagem a Dilma Solange Napp, revisora minuciosa dos nossos manuscritos, a quem devemos inúmeras gentilezas.

Cabeça com tegumento preto. Fronte revestida por pubescência predominantemente castanho-amarelada. Lados da cabeça com pubescência marrom-amarelada entremeada por pubescência branca. Lobos oculares inferiores tão longos quanto as genas. Escapo com pubescência marrom-amarelada predominante no lado interno e pubescência branca entremeada por escassa pubescência marrom-amarelada no lado externo. Antenômero III com a metade basal revestida por pubescência esbranquiçada e a metade apical por pubescência castanho-amarelada. Demais antenômeros acastanhados com anel basal de pubescência branca.

Protórax com pubescência mesclada, branca e castanho-amarelada. Pubescência do pronoto entremeada por pontos castanhos contrastantes, principalmente na metade posterior. Pronoto com quatro gibosidades situadas à frente do meio e sublinhadas; a gibosidade central glabra, longitudinal e menos acentuada do que as outras.

Escutelo com pubescência esbranquiçada nos lados e castanho-amarelada no centro. Élitros (Fig. 1) com a declividade basal coberta por pubescência branca, entremeada por pontos tuberculiformes escassos; crista centro-basal pouco notável, com alguns pontos. Pubescência elitral desde as cristas basais até o meio, 
predominantemente castanho-amarelada; metade apical com a mesma pubescência, porém mais entremeada por manchas irregulares de pubescência branca. Úmeros projetados, seguidos por elevação glabra em pequena extensão.

Face ventral do corpo com pubescência esbranquiçada, mais entremeada por pubescência acastanhada nos escleritos laterais. Urosternitos com a região central preta e glabra; nos lados, com pubescência castanho-amarelada.

Profêmures com pubescência branca no lado externo e predominantemente castanho-amarelada no lado interno. Meso- e metafêmures com pubescência esbranquiçada na base e pubescência castanho-amarelada na clava e em mancha apical. Tíbias com pubescência castanho-amarelada e anel central de pubescência esbranquiçada.

Dimensões em mm, holótipo §. Comprimento total, 15,7; comprimento do protórax, 2,6; maior largura do protórax (base), 4,6; comprimento do élitro, 12,0; largura umeral, 7,4.

Material-tipo. Holótipo \&, Brasil, Mato Grosso (?), sem outros dados, S. Rohde col. (MZSP).

Discussão. Hypsioma solangeae sp. nov. distingue-se de Hypsioma steinbachi Dillon \& Dillon, 1945 pela pubescência do pronoto variegada de castanho e esbranquiçado e pela pubescência da base dos élitros branca. Em H. steinbachi, o pronoto é todo coberto por pubescência esbranquiçada e a base dos élitros não tem faixa de pubescência branca que está presente apenas sobre os úmeros. Difere de H. chapadensis Dillon \& Dillon, 1945 (que apresenta faixa de pubescência esbranquiçada na base dos élitros) pelo aspecto geral mais robusto e compacto e pela gibosidade da base dos élitros mais estreita e menos oblíqua. Em H. chapadensis, o corpo é mais esbelto e as gibosidades basais dos élitros são mais alongadas e oblíquas.

\section{Hypsioma cariua sp. nov.} (Fig. 2)

Etimologia. Tupi, caríua $=$ poderoso, alusivo ao corpo robusto.

Tegumento corporal preto. Fronte com pubescência castanha e pequenas manchas esparsas de pubescência amarelada. Vértice coberto por pubescência branco-amarelada. Entre os lobos oculares superiores, duas faixas de pubescência castanha; parte lateral da cabeça com pubescência predominantemente amarelada. Lobos oculares inferiores sensivelmente mais curtos do que as genas. Escapo preto com anel central e mancha dorso-apical de pubescência alaranjada. Flagelômeros pretos com anel basal de pubescência branca.

Protórax coberto por pubescência esbranquiçada e amarelada. Partes laterais do protórax com pubescência branco-alaranjada. Pronoto com quatro tubérculos anteriores, pouco projetados; gibosidade centro-basal estreita, longitudinal e glabra; alguns pontos contrastantes junto à orla anterior e nos lados da base.

Élitros (Fig. 2) com pubescência branco-amarelada até o nível posterior das gibosidades basais; região sutural do quarto anterior com muitos pontos contrastantes; região anterior da crista com quatro ou cinco tubérculos glabros; região atrás da faixa clara basal até o meio, fortemente pontuada; metade apical coberta por pubescência amarelada entremeada por algumas faixas estreitas e longitudinais, que não atingem o ápice, de pubescência castanha.

Fêmures com tegumento preto e anel apical de pubescência amarelada; os meso- e metafêmures com pubescência amarelada na base. Mesotíbias pretas com anel central de pubescência de amarelada. Metatíbias com a base preta e o restante recoberto por pubescência amarelada.

Esternos torácicos cobertos principalmente por pubescência amarelada. Urosternitos glabros no centro, com apenas alguns pêlos isolados; nos lados, com pubescência amarelo-alaranjada.

Dimensões em mm, holótipo \&. Comprimento total, 16,9; comprimento do protórax, 2,7; maior largura do protórax (base), 4,6; comprimento do élitro, 12,8; largura umeral, 7,5.

Material-tipo. Holótipo \&, Bolívia, Santa Cruz: Amboro Road above Achira Campo (5-5800 pés), 9-11.X.2004, Morris \& Wappes col. (MNKM).

Discussão. Hypsioma cariua sp. nov. difere de $H$. sororcula Martins, 1981 pela região central dos urosternitos glabra com alguns pêlos muito esparsos; pelas faixas estreitas e longitudinais de pubescência castanha na metade apical dos élitros; pelo tubérculo central do pronoto glabro e situado atrás dos anteriores. Em $H$. sororcula, a região central dos urosternitos é coberta por pubescência acastanhada; a pubescência da metade apical dos élitros não está organizada em faixas; o tubérculo central do pronoto é pubescente e situa-se próximo aos anteriores.

\section{Oncideres fulvoguttata Dillon \& Dillon, 1946 (Fig. 3)}

Oncideres fulvoguttata Dillon \& Dillon, 1946: 356, est. 14, fig. 4; Monné, 2005: 577 (cat.).

Depois da descrição original, baseada em materialtipo procedente do Brasil (Pará e Amazonas), $O$. fulvoguttata só teve menções de catálogos (BREUNING, 1961; Monné, 2005). A figura de Dillon \& Dillon (1946) é um esquema do pronoto e dos élitros e a publicação do habitus (Fig. 3) permite o reconhecimento da espécie de forma mais precisa.

Examinamos uma fêmea (Fig. 3) do Brasil, Amazonas: Manaus (Reserva Ducke, 26 km N), 23.III.1996, J. G. Hurtado col., em choque de inseticida em Eschweilera pseudodecolorans (MZSP).

\section{HEMIILOPHINI Piratininga mocoia sp. nov.} (Fig. 4)

Etimologia. Tupi, mokõîa $=$ segundo, por ser a segunda espécie descrita no gênero Piratiniga.

Cabeça preta; fronte, genas e gula, amareladas cobertas por pubescência da mesma cor; região entre os tubérculos anteníferos com pubescência avermelhada. Vértice com uma faixa centro-longitudinal de pubescência amarelada. Antenas pretas, quase atingem a ponta dos élitros; são amareladas: metade apical do antenômero IV; antenômeros V-VII, menos anel apical, preto; anel basal dos 
antenômeros VII-X. Escapo com metade do comprimento do antenômero III, este com mais do que o dobro do comprimento do IV; antenômeros seguintes com comprimentos gradativamente decrescentes. Antenômeros III e IV com pêlos pretos, longos, em toda a superfície; antenômeros seguintes com franja esparsa na margem

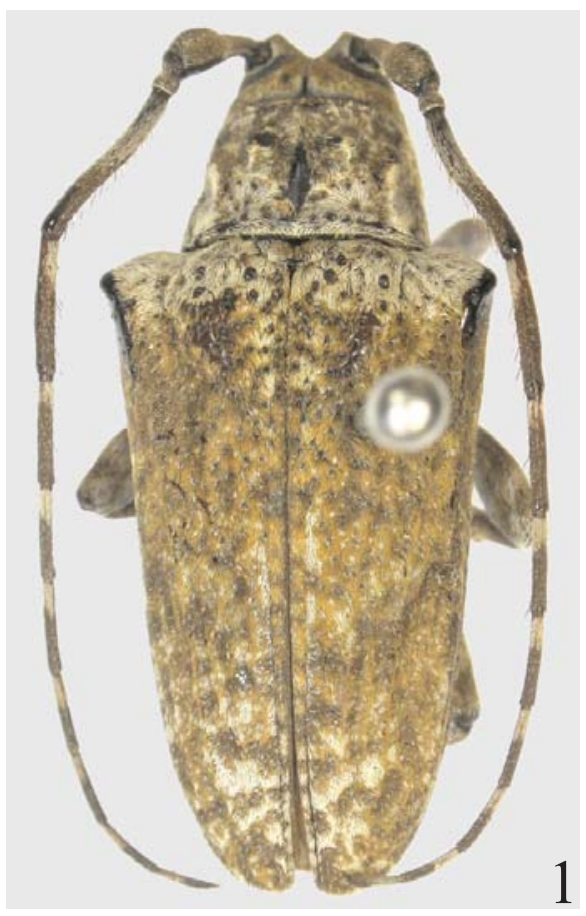

interna e um pêlo longo no ângulo externo-apical (antenômero XI perdido).

Protórax preto, mais largo do que longo, apenas abaulado no meio dos lados; pronoto (Fig. 4) revestido por densa e longa pubescência avermelhada, exceto numa faixa transversal junto da base. Partes laterais do protórax com o

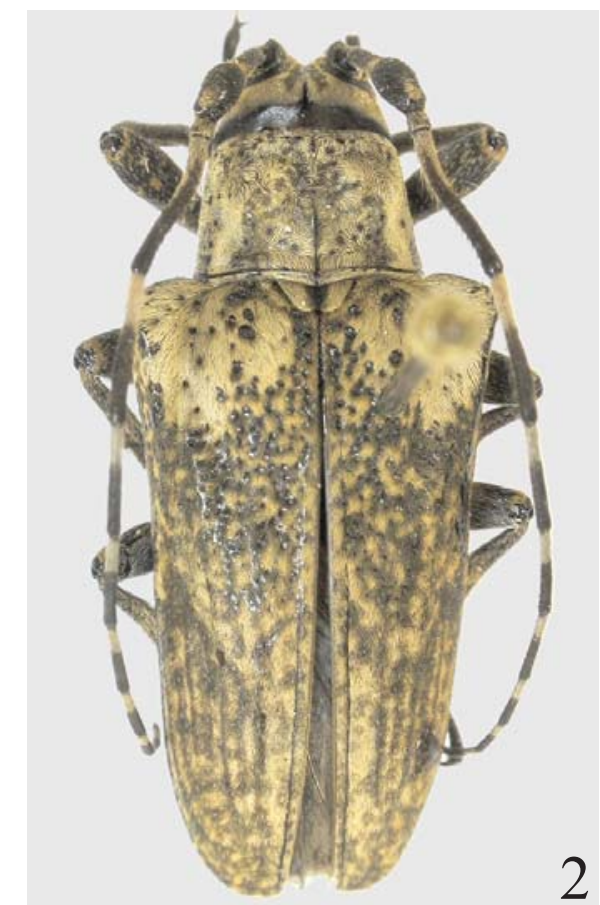

Figs. 1-2. Habitus. 1, Hypsiona solangeae sp. nov., holótipo $\subsetneq$, comprimento 15,7; 2, Hypsioma cariua sp. nov., holótipo $\subsetneq$, comprimento $16,9 \mathrm{~mm}$.
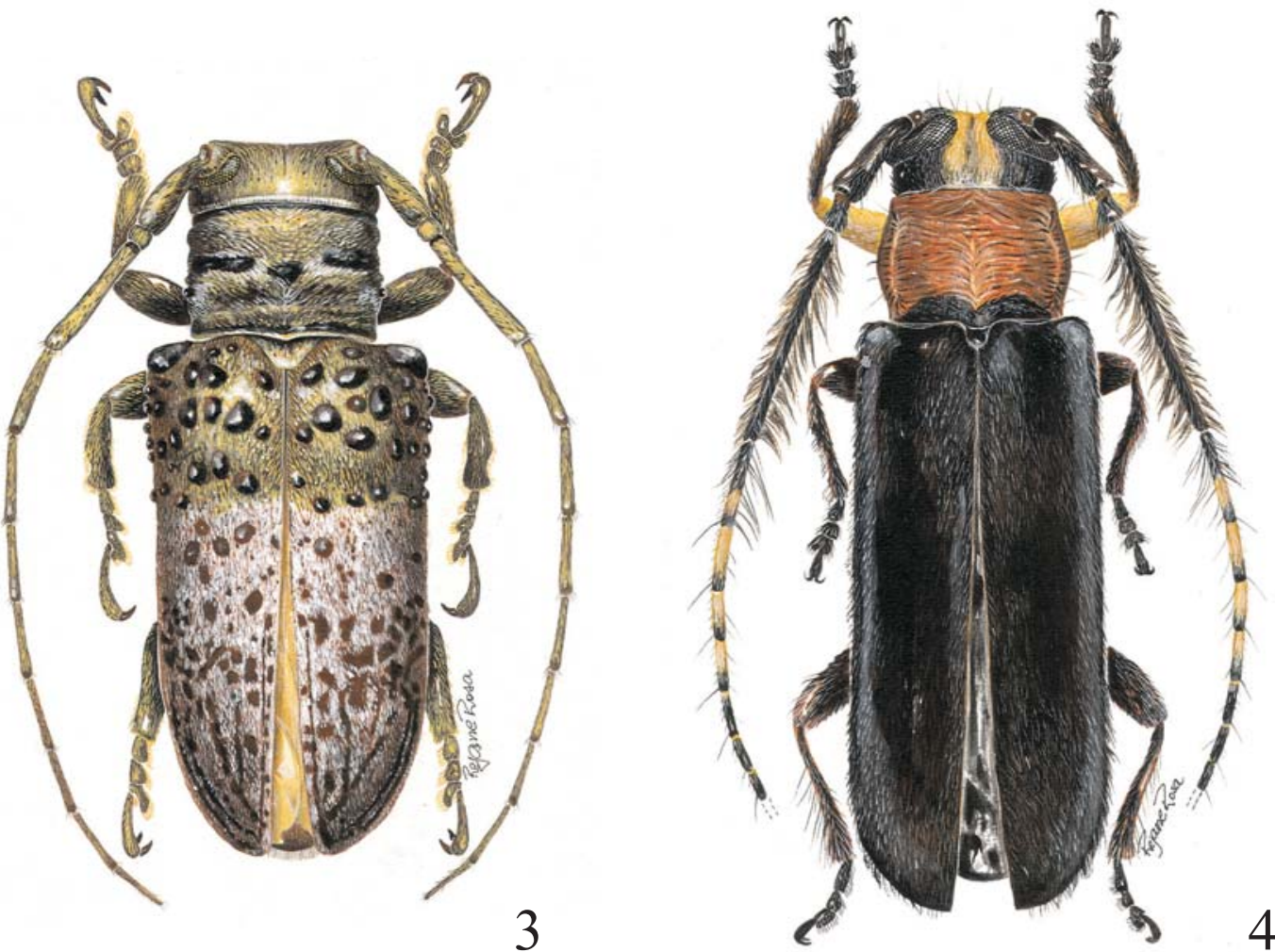

Figs. 3-4. Habitus. 3, Oncideres fulvoguttata Dillon \& Dillon, 1946, §; 4, Piratininga mocoia sp. nov., holótipo §, comprimento 8,7 mm. 
mesmo tipo de pubescência. Élitros pretos, pontuados e pubescentes; extremidades arredondadas em conjunto.

Profêmures amarelados e pretos na base; meso- e metafêmures pretos com pequena área basal amarelada. Tíbias e tarsos pretos. Face ventral do corpo preta, revestida por pubescência serícea amarelada, densa.

Dimensões em mm, holótipo . Comprimento total, 8,7 ; comprimento do protórax, 1,6; maior largura do protórax, 2,2; comprimento do élitro, 6,6; largura umeral, 2,6.

Material-tipo. Holótipo $\subsetneq$, BOLÍVIA, Santa Cruz: Buena Vista (4-6 km SSE, Hotel Fauna \& Flora), 15-20.XI.2003, R. Clarke col. (MNKM).

Discussão. Piratininga mocoia sp. nov. difere de P. piranga Galileo \& Martins, 1992 pelo padrão de colorido das antenas, do protórax e dos élitros que não têm faixa amarelada lateral. Em $P$. piranga, as antenas são pretas com anel basal dos antenômeros brancos, o protórax é revestido por pubescência avermelhada entremeada de branco nos lados e os élitros são pretos com uma faixa lateral de pubscência amarelada. Além disso, em P. mocoia a maior largura do protórax é no meio e em $P$. piranga no terço basal.

\section{Eranina piterpe sp. nov. (Fig. 5)}

Etimologia. Tupi, pitérpe = metade , alusivo à faixa amarelada dos élitros.

Cabeça coberta por pubescência amarelada, exceto, atrás dos olhos e numa mancha circular da parte superior da fronte com tegumento preto e glabro. Escapo preto com o lado interno da clava avermelhado. Antenômero III preto; antenômeros IV, V e metade basal do VI com tegumento avermelhado coberto por pubescência branca; antenômero VII-XI pretos.

Protórax preto com as partes laterais, no limite com o prosterno, amareladas. Centro do pronoto coberto por pubescência amarelada.

Élitros (Fig. 5) com o dorso da metade anterior quase glabro, preto; lados com pubescência amarelada, cujo limite posterior é oblíquo da sutura para a margem; restante da superfície elitral com tegumento preto.

Fêmures com a metade basal amarelada e a metade apical preta. Base das protíbias amareladas e o restante preto. Meso- e metatíbias pretas.

Mesepimeros, mesepisternos e metepisterno cobertos por pubescência amarelada. Metasterno e urosternitos pretos.

Dimensões em mm, holótipo \&. Comprimento total, 6,2; comprimento do protórax, 1,0; maior largura do protórax, 1,4; comprimento do élitro, 4,6; largura umeral, 1,9.

Material-tipo. Holótipo ఢ. BOLÍviA, Santa Cruz: Potrerillos del Guendá $\left(17^{\circ} 40,26^{\prime}\right.$ S, 63²7,44'W), 5-20.XI.2004, B. Dozier col. (MNKM).

Discussão. Eranina piterpe sp. nov. difere de Eranina porongaba (Galileo \& Martins, 1998), do Brasil (Santa Catarina), pelas antenas com os antenômeros IV, $\mathrm{V}$ e base do VI brancos; pela faixa amarelada do centro do pronoto quase da mesma largura à frente e atrás; pelos élitros com mancha preta, larga, sutural na metade anterior e limite da parte amarelada lateral oblíquo em sentido descendente da sutura para a margem. Em Eranina porongaba apenas o antenômero IV (exceto o ápice) é branco; a faixa amarelada do meio do pronoto é triangular e não atinge a base e nos élitros, somente a região circumescutelar é preta e o limite entre as partes amarelada e preta é irregular e transversal.

Eranina piterpe sp. nov. distingue-se de Eranina longiscapus (Bates, 1881) pelas antenas com os antenômeros IV, V e base do VI brancos; pelo pronoto sem faixas laterais de pubescência amarelada; pela faixa amarelada dos élitros que se inicia na base e ocupa os lados da metade anterior; pelos mesepimeros, mesepisternos e metepisterno cobertos por pubescência amarelada. Em E. longiscapus, os antenômeros IV e anel basal do V são brancos; o protórax apresenta uma faixa de cada lado de pubescência amarelada; a faixa amarelada é larga, transversal e ocupa o meio dos élitros e os mesepimeros, mesepisternos e metepisternos são pretos.

\section{AERENICINI \\ Phaula atyroa sp. nov. \\ (Fig. 6)}

Etimologia. Tupi, atyrõ = arranjado, enfeitado; alusivo ao arranjo dos grânulos restritos à base dos élitros e moderadamente concentrados.

Tegumento castanho-avermelhado. Fronte revestida por pubescência alaranjada. Lobos oculares superiores mais próximos entre si do que a largura de um lobo. Escapo e pedicelo pretos; flagelômeros avermelhados.

Protórax mais largo do que longo. Pronoto revestido por pubescência predominantemente branca, mas com pubescência alaranjada principalmente ao longo da linha mediana. Escutelo revestido por pubescência alaranjada.

Élitros com pubescência esbranquiçada e duas faixas longitudinais estreitas de pubescência alaranjada: uma junto à margem, do úmero ao ápice, e outra próxima da sutura no terço apical, que não alcança as extremidades. Pontos da base elitral (Fig. 6) moderadamente concentrados e restritos ao sexto basal; restante da superfície com pontos glabros e esparsos. Extremidades elitrais com longo espinho externo.

Fêmures com pubescência branca, nos médios e nos posteriores a pubescência da face inferior é mais amarelada e concentrada. Lados do metasterno com mancha de pubescência amarelada.

Urosternitos com pubescência amarelada e pontos contrastantes pouco visíveis.

Dimensões em mm, holótipo đ. Comprimento total, 18,6; comprimento do protórax, 2,8; maior largura do protórax, 3,0; comprimento do élitro, 14,4; largura umeral, 4,8.

Material-tipo. Holótipo $\sigma^{\prime}$, BRASIL, Mato Grosso do Sul: Selvíria, 9.X.2001, V. O. Becker col. (MZSP).

Discussão. Phaula atyroa sp. nov., pela presença de faixa longitudinal de pubescência alaranjada nos élitros, assemelha-se a $P$. bullula Martins, 1984, P. lichenigera (Perty, 1830) e P. splendida Galileo \& Martins, 1987. Difere de $P$. bullula por apresentar os grânulos concentrados, restritos à base dos élitros e as pontas dos élitros com espinho longo; em $P$. bullula, a área com grânulos concentrados prolonga-se até o meio dos élitros e a 
extremidade elitral é acuminada e sem espinho longo. Distingue-se de P. lichenigera (Fig. 7) pelos grânulos na base dos élitros mais afastados entre si e pela menor concentração dos pontos contrastantes no restante da superfície elitral; pela pubescência do pronoto predominantemente branca com pouca pubescência amarelada entremeada. Em P. lichenigera (Fig. 7), os grânulos da base dos élitros são concentrados, contíguos e com pubescência alaranjada em alguns interstícios; pontos do restante da superfície elitral mais numerosos; a pubescência do pronoto é predominantemente alaranjada.

Phaula atyroa sp. nov. separa-se de $P$. splendida

(Fig. 8) pelos pontos da região basal dos élitros mais esparsos, pelos lobos oculares superiores mais próximos entre si que a largura de um lobo, pela presença de pubescência alaranjada no pronoto. Em P. splendida (Fig. 8), os pontos da região basal dos élitros são concentrados, a distância entre os lobos oculares superiores quase igual ao dobro da largura de um lobo e a pubescência no pronoto é inteiramente branca.
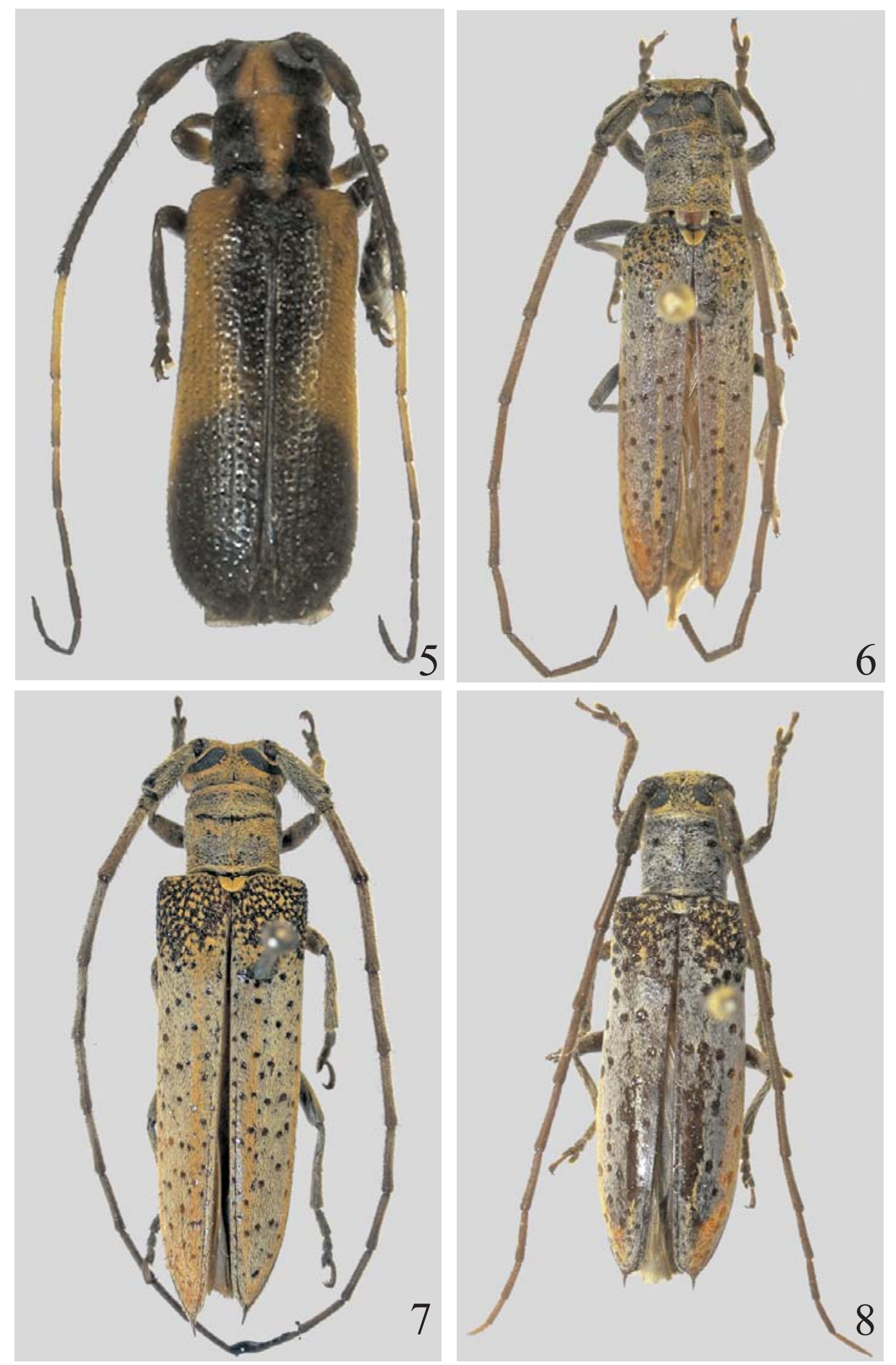

Figs. 5-8. Habitus. 5, Eranina piterpe sp. nov., holótipo 9 , comprimento 6,2 mm; 6, Phaula atyroa sp. nov., holótipo o’, comprimento 18,6 mm; 7, Phaula lichenigera (Perty, 1830), హ, comprimento 24,4 mm; 8, Phaula splendida Galileo \& Martins, 1987, holótipo §, comprimento 17,9 mm. 


\section{Aerenicopsis rejaneae sp.nov. (Fig. 9)}

Etimologia. O nome específico é uma homenagem a Rejane Rosa, desenhista do Museu de Ciências Naturais, que tem ilustrado muitas das nossas contribuições.

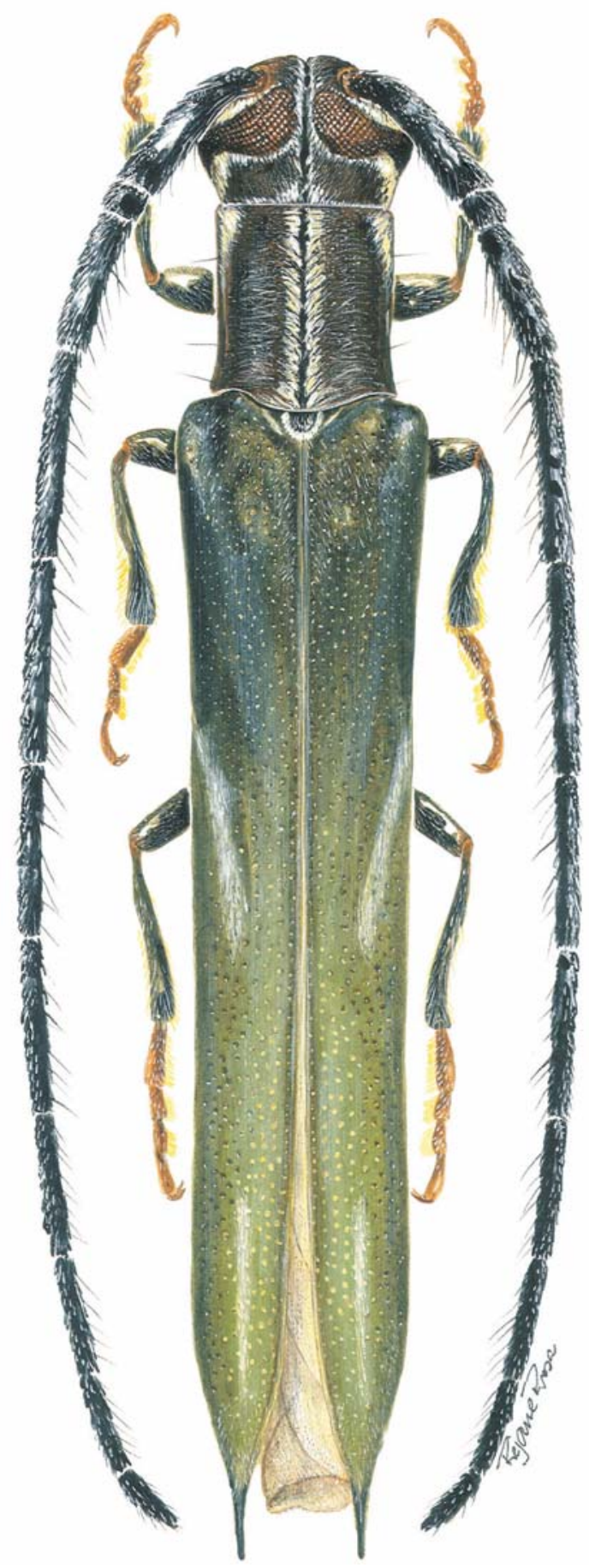

Fig. 9. Habitus, Aerenicopsis rejaneae sp. nov., holótipo उ', comprimento $14,8 \mathrm{~mm}$.
Cabeça com tegumento preto e quatro faixas de pubescência branca: duas no meio, muito próximas entre si, e uma faixa atrás de cada lobo ocular inferior. Olhos não-divididos. Fronte com pubescência esparsa, esbranquiçada. Antenas pretas.

Protórax com quatro faixas de pubescência branca: duas no meio do pronoto, subcontíguas, e uma a cada lado das partes laterais.

Élitros (Fig. 9) com tegumento esverdeado; cada um com duas áreas estreitas de pubescência branca: uma oblíqua em sentido descendente da margem para a sutura no meio e uma longitudinal no quinto apical que atinge os ápices; extremidades prolongadas em espinho longo e preto.

Face ventral com tegumento preto, menos numa faixa que envolve a parte superior do mesepisterno, mesepimero, canto anterior dos metepisterno e curva nos lados do metasterno. Fêmures e tíbias pretos. Tarsômeros avermelhados.

Dimensões em mm, holótipo đ. Comprimento total, 14,8; comprimento do protórax, 1,8; maior largura do protórax, 1,7; comprimento do élitro, 11,5; largura umeral, 2,3.

Material-tipo. Holótipo $\widetilde{\sigma}$, BRASIL, Tocantins: Paranã (Fazenda Caldas, 12 ${ }^{\circ} 56^{\prime}$ S, 47 $57^{\circ}$ 'W, cerrado), 13.X.2004, R. R. Silva \& B. H. Dietz col. (MZSP).

Discussão. Aerenicopsis rejaneae sp. nov. assemelha-se a A. virgata (Pascoe, 1878) e difere pelos lobos oculares superiores muito mais largos, pelas duas faixas subcontíguas de pubescência branca no meio do vértice e do pronoto, pelos élitros com tegumento verde e faixas de pubescência branca, estreitas e dorsais. $\operatorname{Em} A$. virgata, as faixas do centro da cabeça e do pronoto são largas e únicas; os élitros apresentam, às vezes, colorido esverdeado com faixa de pubescência branca longitudinais e contínuas, especialmente a sutural, que se estende da base ao ápice.

Agradecimentos. A James E. Wappes, pelo envio de material para estudo; a Rejane Rosa (Museu de Ciências Naturais, Fundação Zoobotânica do Rio Grande do Sul, MCNZ), pelo preparo das ilustrações a cores e a Rafael Santos de Araujo (MCNZ), pela execução das fotografias.

\section{REFERÊNCIAS BIBLIOGRÁFICAS}

Breuning, S. 1961. Catalogue des Lamiaires du Monde (Col., Cerambycidae). 4 Lief. Tutzing bei München, Museum G. Frey. p. 183-284.

Dillon, L. S. \& Dillon, E. S. 1945. The tribe Onciderini (Coleoptera: Cerambycidae). Part I. Reading Public Museum and Art Gallery, Scientific Publications, 5:XV, 1-186.

1946. The tribe Onciderini (Coleoptera: Cerambycidae). Part II. Reading Public Museum and Art Gallery, Scientific Publications, 6:189-413.

Martins, U. R. \& Galileo, M. H. M. 1998. Revisão da tribo Aerenicini Lacordaire, 1872 (Coleoptera, Cerambycidae, Lamiinae). Arquivos de Zoologia 35(1):1-133.

Monné, M. A. 2005. Catalogue of the Cerambycidae (Coleoptera) of the Neotropical Region. Part II. Subfamily Lamiinae. Zootaxa 1032:1-559.

Recebido em junho de 2006. Aceito em novembro de 2006. ISSN 0073-4721

Artigo disponível em: www.scielo.br/isz 